\title{
Couple emotional dependence as a risk factor in the consumption of psychoactive substances in women
}

\begin{abstract}
The aim of the study is to identify the influence of emotional dependence on the couple as a risk factor in the initiation and maintenance of the psychoactive substances in a sample of 20 women, users of a residential treatment program. For this, a mixed methodology and a concurrent transformative design were used. The results suggest that emotional dependence represents a risk factor for the psychoactive substances, this influence being more significant in the maintenance of the problem than in the beginning of the same. Likewise, the influence of implicit cognitive and behavioral behaviors on these patients is reflected in avoiding dysphoric emotions, pleasing the couple, attracting attention and maintaining the relationship. Based on the findings, it is suggested to include a program to address emotional dependence in order to optimize its effectiveness, both in the treatment activities and in the prevention of drug addiction in women.
\end{abstract}

Volume 2 Issue 4 - 2018

\author{
Jesús Joel Aiquipa Tello, ${ }^{1,2}$ Nelly María \\ Canción Suárez ${ }^{2}$ \\ 'Universidad Inca Garcilaso de la Vega, Perú \\ ${ }^{2}$ Institution Vida Mujer, Perú
}

\author{
Correspondence: Jesus Joel Aiquipa Tello, Psicólogo, \\ Universidad Inca Garcilaso de la Vega, Sucre 224, San Martín de \\ Porres, Lima, Perú, Tel +51997258107,
}

Email jesus.aiquipat@gmail.com

Received: June 25, 2018 | Published: July 10, 2018

Keywords: emotional dependence, couple of psychoactive substances, treatment, risk factor, drug addiction, women, psychoactive substances, physiological changes, consumption of psychotropic, intoxication, dementia symptoms

\section{Introduction}

It is understood by psychoactive substances (hereinafter SPA) any substance that produces physical and physiological changes in the central nervous system, thus altering the psychological functions of the subject. ${ }^{1}$ The use or consumption of psychoactive substances would be the intake of these drugs to the body by the subject, most of the time on a voluntary basis, to achieve a desired effect by the same. When a poorly adaptive pattern of consumption of the substance with a clinically significant level of deterioration is observed, it already configures the mental and behavioral disorders due to the consumption of psychotropic substances, ${ }^{2}$ Its severity ranges from uncomplicated intoxication and harmful consumption to manifest psychotic and dementia symptoms. The United Nations Office on Drugs and $\mathrm{Crime}^{3}$ It estimates that around 250 million people $(5 \%$ of the adult population) used drugs at least once in 2015. Also, this report refers that about 29.5 million of those consumers $(0.6 \%)$ suffered from disorders caused by the use of drugs. In Peru, Zavaleta, Tapia, Rojas, Barco, \& Chávez, ${ }^{4}$ found that the lifetime prevalence of legal drugs for alcoholic beverages was $82.1 \%$, while in the case of tobacco was $54.8 \%$. Regarding illegal drugs, it was observed that marijuana $(7.5 \%)$ was the substance with the highest prevalence of life, followed by basic cocaine paste $(2.9 \%)$ and cocaine hydrochloride $(2.4 \%)$. Likewise, $4.1 \%$ of respondents reported having received at least one offer to consume ecstasy, $1.0 \%$ received an offer to use heroin and $0.3 \%$ to consume opium.

Regarding the etiology of drug dependencies, there is a consensus of the international scientific community that considers it multifactorial, adopting the risk factor approach (contextual or personal situations that increase the probability of consuming SPA) to study it and propose more effective and viable solution alternatives. ${ }^{5,6}$ In this way, it is appropriate to consider the influence of risk factors such as age, sex, gender, family, personality characteristics, among other points. A qualitatively differentiating aspect regarding the consumption of psychoactive substances is the variable sex and its social correlate gender. The volume of research that integrates this element in the existing literature on the subject is increasing. Thus, differences were found in the pattern of consumption, with women often using medical drugs ${ }^{7}$ they are more vulnerable to certain effects of the SPA, tend to be at greater risk of dependence and are more susceptible to relapse ${ }^{8}$ they are more vulnerable than men to risky behavior $^{9}$ its consumption is related to personal meanings regarding their experiences, the influence of their partners, feelings of loneliness and / or abandonment, evasion or survival in the face of problems and sexual abuse experienced. ${ }^{10}$ At the level of personality, a relevant dimension for the study of the use of SPA in women is the affective dimension in their relationships. Starting from the premise that women often give greater importance to this issue with respect to the male, and knowing that women are more susceptible to some Depend relational dence with a partne ${ }^{10}$ little considered explicitly the influence you may have Emotional dependence in many of the mental disorders of the female population, and in the consumption of psychoactive substances in particular. ${ }^{11}$

Emotional dependence is defined as the need for bonding extreme that a person feels toward his partner. ${ }^{12,13}$ This need would configure a dysfunctional personality trait. ${ }^{14,15}$ Like all traits, it implies a persistent pattern of thinking, feeling and acting with respect to the couple's relationship that are maladaptive and that generates discomfort to the subject who suffers. ${ }^{16}$ This pattern would include, among other issues, beliefs about the vision of oneself and the other, as well as interpersonal behaviors aimed at maintaining relational closeness in a way that is even harmful to oneself. ${ }^{12}$ Thus, in the context of the following study, a woman who has emotional dependence devotes a lot of time to the relationship, desperately seeks the welfare of the other, the absence of the couple means for her a situation of discomfort and discomfort, is afraid of abandonment, separation and loneliness, tends to postpone and even deny their desires and need is to satisfy those of the other. ${ }^{12-17}$ In that sense, it is likely that a woman with emotional dependence start your SPA consumption to please your partner and feel united to him ${ }^{10-18}$ increase your consumption with the couple; ${ }^{19}$ consume to cushion and emotional distress because of the crisis, dissatisfactions, threats of rupture and no emotional correspondence..$^{20}$ In addition, they may not access treatments because they fear losing 
their relationship with their partner; ${ }^{21}$ and they remain in relationships even though they are violent, because they depend on him and because he provides them with SPA. ${ }^{22}$

Although some researchers identify as one of the risk factors the woman consumer problems or conflicts with your partner (whether or not drug user), not what dimension or component is required is a factor in the initiation or maintenance consumption of psychoactive substances. This means that these studies are ambiguous and therefore precision is lost when studying this phenomenon. As a result, it does not focus well on what aspect of the woman according to the couple has to be addressed in the therapeutic process and in the prevention of the problem. In this way, the study of emotional dependence as a possible psychological risk factor that involves the relational aspect has not been thoroughly reviewed. It has only been mentioned tangentially within a more general appreciation and implicitly the influence that this variable could have on the consumption of SPA in women. On the other hand, for the purposes of the following study, it was considered convenient to use a mixed approach, since the study of emotional dependence and the consumption of psychoactive substances in women represent such complex issues that the use of a single approach ( quantitative or qualitative ) would be limited to achieve an understanding of these phenomena. As described, the present empirical research is perhaps one of the first to explicitly address the role of emotional dependence on the couple in the use of SPA in women. Consistently, the study objective and s identify the influence of emotional dependence to the couple as a risk factor in consumption and psychoactive $\mathrm{d}$ in women using a program of residential treatment substances.

\section{Methodology}

\section{Research design}

A mixed approach with a concurrent transformative desig ${ }^{23,24}$ was used, since quantitative and qualitative data were collected and analyzed at the same time (concurrent), and these processes were guided by a theoretical perspective, which in this case was the model of risk factors and the model of emotional dependence. It is pertinent to point out that these types of designs are increasingly used in the area of mental health, due to the complex nature of this issues. ${ }^{25}$

\section{Participants}

The type of sampling was intentional. For the first stage of the study, there were two samples. One of them consists of 20 women between 18 and 60 years, who made up the study sample with an average age of 30 years, $85 \%$ from Lima, with a level of technical and university higher education (75\%), girls in their majority $(80 \%)$ of different socioeconomic level, with a minimum level of reading comprehension, who have had at least one heterosexual relationship during their life, with problematic use of SPA and that they are users of the residential treatment program in the Institución Vida Mujer, province and department of Lima, Peru (Table 1). The other sample, called a comparison sample, consisted of 16 women (mean age 25 years) with the same criteria of the study sample except that had different problems with problematic use of SPA (eating disorders, personality disorders, depression and anxiety disorders) who at most had an experimental consumption. Subsequently, for the second stage, only the collaboration of the study sample was counted; that is, the 20 women with SPA consumption.
Table I Characteristics of the sample

\begin{tabular}{|c|c|c|c|}
\hline Variables & Categories & $\mathbf{N}$ & $\%$ \\
\hline \multirow[t]{2}{*}{ Age } & Youth: I7-24 years & 9 & 4.5 \\
\hline & Young Adults: 25-34 years & 5 & 25 \\
\hline \multirow[t]{3}{*}{ ( M: 30.4; DS: 12.08) } & Adults Average: $35-44$ years & 2 & 10 \\
\hline & Older Adults: $45-60$ years & 4 & 20 \\
\hline & Lima & 17 & 85 \\
\hline \multirow[t]{3}{*}{ Place of birth } & Province & 2 & 10 \\
\hline & Exterior of the country & 1 & 5 \\
\hline & Single & 16 & 80 \\
\hline \multirow[t]{3}{*}{ Civil status } & Married & 2 & 10 \\
\hline & Divorcee & 2 & 10 \\
\hline & High school & 5 & 25 \\
\hline \multirow[t]{3}{*}{$\begin{array}{l}\text { Level of educational } \\
\text { instruction }\end{array}$} & Superior Technician & 5 & 25 \\
\hline & University Superior & 10 & 50 \\
\hline & Yes & 6 & 30 \\
\hline Current couple & Do not & 14 & 70 \\
\hline Total & & 20 & 100 \\
\hline
\end{tabular}

\section{Techniques and the data collection instruments}

It was used interview not individual structured and focal group, counting for it with interview guides with central themes such as situations that led to the initiation and maintenance of drug misuse, as well as the dynamics and experiences in their relationships. Medical history of the patients, written documents of users with related topics research was also used. As a quantitative instrument, the Inventory of Emotional Dependence- IDE ${ }^{14,15}$ was used, which has been created and validated in Peru, based on the model of personality traits and the theoretical model of Castelló. ${ }^{12}$ The test contains 49 items on a Likert scale of 5 alternatives, grouped into seven factors: fear of rupture (MR), fear and intolity to loneliness (MIS), priority of the couple (PP), need to access the couple (NAP), desire for exclusivity (DEX), rdinación upload and submission (SS) and desires control and domain (DCD). INDICATORS has satisfactory reliability's (Crombach's alpha $=0.96$ and corrected Pearson's $r=0.91$ ), as well as evidence of adequate construct validity (Rates concordance between 0.80 and 1.00 for more than $95 \%$ of the reactants, reproduction 7 factors that accounted for $58.25 \%$ of the total variance with items with saturations between 0.40 and 0.70 and evidence of criterion validity to $95 \%$ confidence level).

\section{Process}

The possible participants, dates and times for the data collection were coordinated with the Institution. The verbal and written consent of the participants was requested. Within the scheduled time, the work sessions were conducted with two groups (11 and three members, respectively) and with the other participants (six) individually. For the larger group, four sessions were used (with a time of $120 \mathrm{~min} /$ session), for the smaller group three sessions ( $90 \mathrm{~min} / \mathrm{session}$ ) and for the individual interview two sessions were used for each participant (60 $\mathrm{min} / \mathrm{session})$. The interviews were used in the environments of 
the institution (wide, illuminated and ventilated). A written activity was assigned to all participants on a topic related to the study (written document). Parallel the medical records were reviewed and the Inventory of Emotional Dependency - IDE ${ }^{14,15}$ was applied to the study and comparison sample.

\section{Data processing}

The techniques for analyzing the data are conformed by quantitative and qualitative techniques. Thus, descriptive statistics were used, nonparametric test for in dependent Mann-Whitney U test samples table with bidimiensional gency and correlation coefficient Lambda, since it allows estimating the association and strength thereof, eliminating the effect of sample size and reducing the proportion of the prediction error regarding Classification of cases with respect to the categories of the variables. The qualitative technique for analyzing the data was the content analysis. For this, the data was encoded in a first level or plane, selecting the sentence or sentence of the segments or units of analysis of the flow; categories were created and their rules were defined taking into account the information found in the data and the theoretical framework of the study. Then the analysis units were located to the corresponding categories. The analysis was carried out at a second level or level, comparing the categories obtained in the previous analysis, identifying in turn some similarities, differences and possible links between them (for example, dysphoric emotions, avoidant behaviors, compensatory strategies, etc.). For this, representative units of each category were recovered in order to understand the essential meaning of the same. The central themes of the analysis were obtained (categories with greater conceptual amplitude). Finally, the interpretations of the general categories were carried out in aspects such as their description, their interrelations and the meaning for the participants, creating a classification system that derives in explanatory models of the problem. For this, visual representations were used.

\section{Ethical appearance}

The results obtained are the product of a systematic, critical and empirical process carried out by the authors. Therefore, their data have been obtained from a part of reality, have been derived from the information of a group of people through specific techniques and have been analyzed and discussed meticulously. Likewise, the contributions of other researchers have been adequately indicated both in the text and in the references. The protection of the welfare and dignity of the participants was guaranteed through verbal and written informed consent as well as confidentiality.

\section{Results}

\section{Consumption pattern}

Table 2 indicates the consumption pattern or profile. It can be seen that $100 \%$ of the participants have had a level of consumption of abuse or dependence, $80 \%$ are polyconsumers, and this consumption has been alone or in the company of their partner $(70 \%$ and $45 \%$, respectively), in their houses $(80 \%)$ and / or fun places $(55 \%)$.

\section{Risk factors}

Tables $3 \& 4$ present the emerging categories regarding the risk factors that facilitate or perpetuate the problematic use of SPA. The most relevant subcategories of the facilitating risk factors of the beginning of consumption of SPA were the risk groups and places (consumption groups and places of sale and / or consumption, respectively). Regarding the risk factors category maintainers of the consumption of SPA, $90 \%$ of the informants indicated that it is the emotional dependence subcategory to the couple that factor that caused his consumption to be maintained; $55 \%$ referred to the conflicts and family discussions (family factor); again the subcategories groups and places of risk (contextual factors) were indicated as important, both having a frequency of $50 \%$.

Table 2 SPA consumption pattern of the sample

\begin{tabular}{|c|c|c|c|}
\hline Variables & Categories & $\mathbf{N}$ & $\%$ \\
\hline \multirow{3}{*}{$\begin{array}{l}\text { Consumption } \\
\text { Level }\end{array}$} & $\begin{array}{l}\text { Experimental and/or } \\
\text { occasional }\end{array}$ & 0 & 0 \\
\hline & Abuse & 8 & 40 \\
\hline & Dependence & 12 & 60 \\
\hline \multirow{3}{*}{$\begin{array}{l}\text { Type of } \\
\text { consumption }\end{array}$} & Monoconsumption & 4 & 20 \\
\hline & Polydrug use & 16 & 80 \\
\hline & Without company & 14 & 70 \\
\hline \multirow{3}{*}{$\begin{array}{l}\text { Relational } \\
\text { context of } \\
\text { consumption a }\end{array}$} & Couple & 9 & 4.5 \\
\hline & $\begin{array}{l}\text { Partners (as) and/or } \\
\text { Friends (as) }\end{array}$ & I & 5 \\
\hline & Home & 16 & 80 \\
\hline \multirow{3}{*}{$\begin{array}{l}\text { Place of } \\
\text { consumption a }\end{array}$} & $\begin{array}{l}\text { Fun places (discos, bars, } \\
\text { etc.) }\end{array}$ & II & 55 \\
\hline & Street & 4 & 20 \\
\hline & Job & I & 10 \\
\hline Total & & 20 & 100 \\
\hline
\end{tabular}

Table 3 Risk factors that facilitated the start of SPA consumption

\begin{tabular}{|c|c|c|c|}
\hline Categories & Subcategories & $\mathbf{F} \mathbf{a}$ & $\%$ \\
\hline \multirow[t]{5}{*}{$\begin{array}{l}\text { Contextual } \\
\text { factors }\end{array}$} & I. Pressure of the peer group. & I & 5 \\
\hline & $\begin{array}{l}\text { 2. Risk groups (consumption } \\
\text { groups) }\end{array}$ & 20 & 100 \\
\hline & $\begin{array}{l}\text { 3. Places of risk (places of sale } \\
\text { and/or consumption). }\end{array}$ & 20 & 100 \\
\hline & 4. Consumer families. & 1 & 5 \\
\hline & 5. Conflicts and family discussions. & 4 & 20 \\
\hline \multirow[t]{5}{*}{ Family factors } & $\begin{array}{l}\text { 6. Physical and/or emotional } \\
\text { distancing of family members. }\end{array}$ & 2 & 10 \\
\hline & 7. Illness and/death of a relative. & 2 & 10 \\
\hline & $\begin{array}{l}\text { 8. Search for attention and } \\
\text { affection of parents. }\end{array}$ & 4 & 20 \\
\hline & $\begin{array}{l}\text { 9. Search for attention and group } \\
\text { approval. }\end{array}$ & 3 & 15 \\
\hline & I0. Intolerance to loneliness. & 2 & 10 \\
\hline \multirow[t]{5}{*}{$\begin{array}{l}\text { Personal } \\
\text { factors }\end{array}$} & $\begin{array}{l}\text { I I.Avoid dysphoric or unpleasant } \\
\text { emotions. }\end{array}$ & 9 & 4.5 \\
\hline & 12. Search for new situations. & 2 & 10 \\
\hline & 13. Experiences of sexual abuse. & 2 & 10 \\
\hline & $\begin{array}{l}\text { 14. Avoid taking responsibility and/ } \\
\text { or facing situations. }\end{array}$ & 4 & 20 \\
\hline & $\begin{array}{l}\text { 15. Characteristics of emotional } \\
\text { dependence. }\end{array}$ & 10 & 50 \\
\hline Total sample & & 20 & 100 \\
\hline
\end{tabular}

aThe sum of the frequencies is not the total of the sample. 
Table 4 Risk factors maintaining SPA consumption

\begin{tabular}{llll}
\hline Category & Subcategories & F a & $\%$ \\
\hline \multirow{2}{*}{ Contextual factors } & I. Risk groups. & 10 & 50 \\
& 2. Places of risk (places of sale and/or consumption). & 10 & 50 \\
Family factors & 3. Conflicts and family discussions. & $1 \mathrm{I}$ & 55 \\
& 4. Search for attention and approval of the group. & 5 & 25 \\
& 5. Intolerance to loneliness. & 6 & 30 \\
Personal factors & 6.Avoid dysphoric or unpleasant emotions. & 6 & 30 \\
& 7. Avoid taking responsibility and/or facing situations. & 3 & 15 \\
& life. Inappropriate management of free time/routine perception of & 8 & 40 \\
Total sample & 9. Inadequate management of work and/or academic stress. & 3 & 15 \\
\hline
\end{tabular}

${ }^{a}$ The sum of the frequencies is not the total of the sample.

Relationship between emotional dependence and consumption of psychoactive substances

Table 5 provides the value of the Mann-Whitney $U$ test (316.0) and its respective level of significance $(p<0.05)$.

Table 6 shows the coefficient of association or Lambda relation, which assumes values greater than 0.50 in its three conditions, with their respective levels of significance $(p<0.05)$. We found that there are significant differences ( $95 \%$ confidence level) between the study sample and a comparison sample, being the first group (problematic use of psychoactive substances) the highest score obtained in the variable emotional dependence. Likewise, it can be seen that there is a strong and high relationship between the research variables, adopting the relationship coefficient with a higher value (0.94) when the consumption of psychoactive substances is considered as a dependent variable.

Table 5 Difference in emotional dependence scores according to the type of sample

\begin{tabular}{lllll}
\hline Type of sample & $\mathbf{N}$ & $\begin{array}{l}\text { Average range } \\
\text { (emotional dependence) }\end{array}$ & $\begin{array}{l}\text { Test } \\
\text { Mann-Whitney U }\end{array}$ & Sig. \\
\hline study & 20 & 26.3 & & $.000^{*}$ \\
Comparison & 16 & 8.75 & 316 & \\
Total & 36 & & & \\
\hline
\end{tabular}

*p $<.05$

Table 6 Coefficient of relationship between study variables

\begin{tabular}{llll}
\hline $\begin{array}{l}\text { Relationship } \\
\text { coefficient }\end{array}$ & Options & Value & Sig. \\
\hline \multirow{3}{*}{ Lambda } & Symmetric & 0.79 & $.000^{*}$ \\
& Consumption of SPA as a dependent & 0.94 & $.000^{*}$ \\
$\mathrm{~N}$ & Emotional dependence as a dependent & 0.65 & $.000^{*}$ \\
\hline
\end{tabular}

$*_{\mathrm{p}}<.05$

Explanatory processes of emotional dependence as a risk factor in the consumption of psychoactive substances

The topics of psychoactive substance use were identified and emotional dependence as central or general categories and the dimensions that make up the latter as subcategories. Likewise, subcategories emerged as cognitive and behavioral strategies, pleasing the couple, dysphoric emotions, risk behaviors, avoidance behaviors, consuming partner, intensification, and upheaval, assuming responsibilities, beliefs and / or irrational ideas about loneliness, compensatory behaviors and affective correspondence. Figure 1 shows how the dimensions of emotional dependency, need for access to the couple and wishes of control and mastery, they influence the consumption of SPA. The first of them refers to the problems of keeping the couple in mind at all times, either physically or through thoughts. The second dimension consists in the active search for attention and affection to capture the control of the couple's relationship, in order to ensure their permanence: 


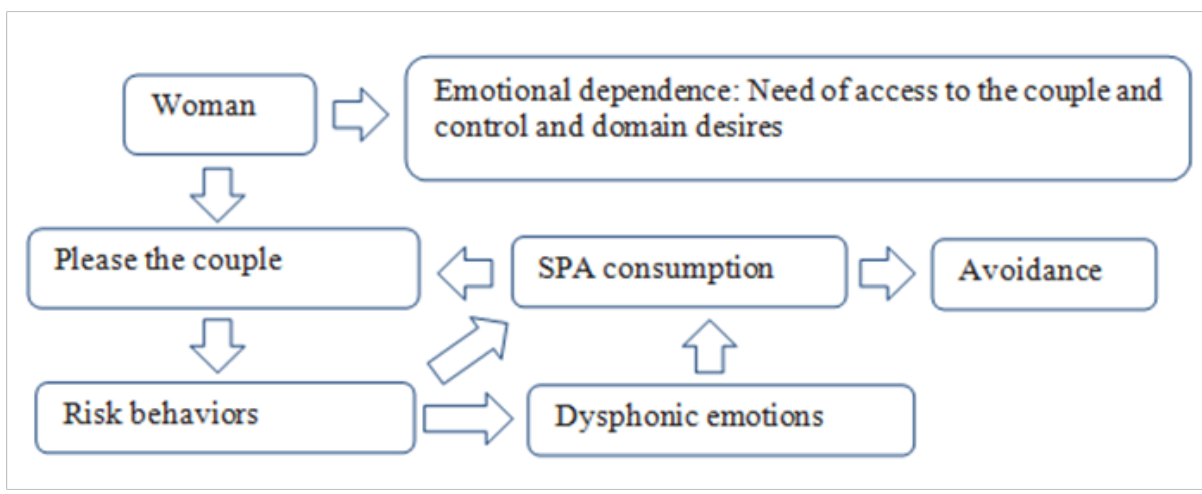

Figure I Consumption of SPA, need of access to the couple and control and domain desires.

"For example, my consumption with cocaine, I started because with that I knew I could lose weight more, I'm going to be skinny, because that's the way he likes it "(18 years old).

"I prostituted myself to pay her whims. I used to forget what I did with people I did not want to be. It made me sick "(26 years old).

"I also thought that he would come back with me if he was my first time. It was the worst experience of my life. I felt bad, with guilt. There worse, I started to consume more "(21 years).

The fear of rupture dimension is defined as the fear experienced by the woman with emotional dependence before the idea of dissolution of the relationship, adopting behaviors to maintain the same, refusing to accept the reality when a rupture becomes reality or exercising continuous attempts to resume the relationship. This dimension is one of the factors that increase the possibility of consuming SPA as shown in Figure 2 and in the units of analysis:

"In the end I find out that she is getting married ... that she is going to have a child. There I explode. I start to leave again, the drink starts, I start going back to parties "(25 years).

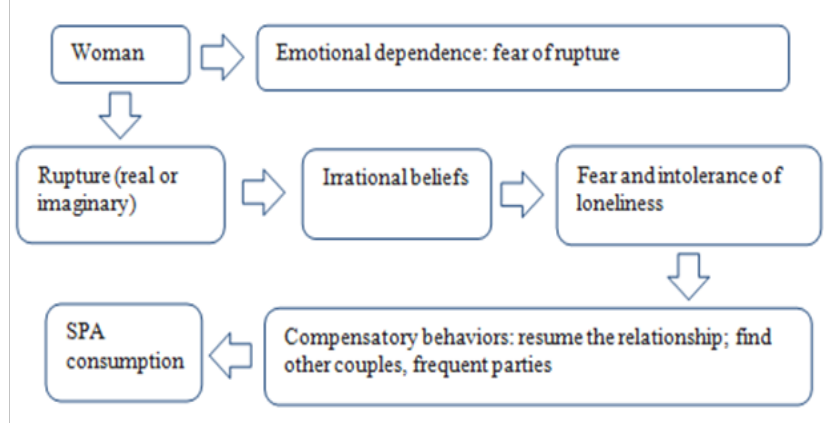

Figure 2 Consumption of SPA, breakup of couple and fear and intolerance to loneliness.

"When he did not listen to me, I suffered horrible. That's when I started a horrible consumption. I threw myself into abandonment "(31 years old).

"I was married for 27 years and when I got divorced I could not stand it. There began the hook with the drug "(53 years).

"When I felt that the relationship with my last partner was not going for more, I was not going to endure a duel of the magnitude I had suffered before. That's where I start to relate more, to get that false security with drugs and with all that group of people "(24 years old).
Figure 3 shows the desire for exclusivity, defined as the tendency to focus on the couple and gradually isolate them from the environment. The subordination and submission dimension is also appreciated, defined as overestimation of the couple's behaviors, thoughts, feelings and interests, accompanied by feelings of inferiority and contempt towards oneself. Both factors dependence emotional facilitate problematic use of SPA:

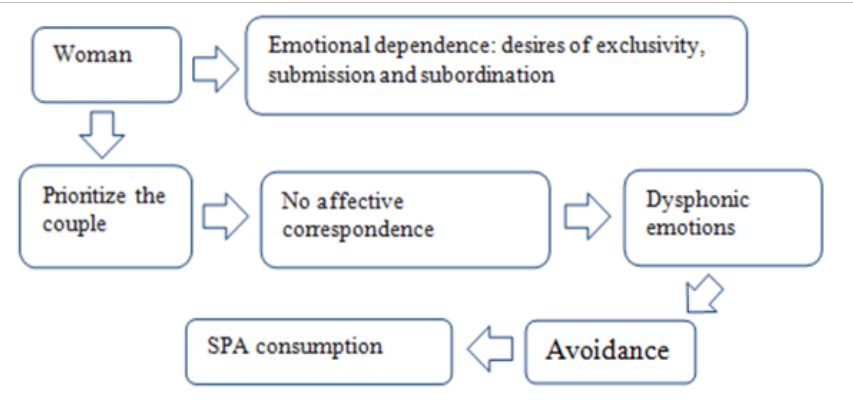

Figure 3 SPA consumption, emotional dependence and affective correspondence.

"It bothered me that my daughter was going with her dad. That he no longer told me 'let's go for a walk', 'let's go out', that bothered me; then that motivated him to buy and drink alcohol "(43 years old).

"That happened to me, given so much to my partner and told me 'hey do your stuff'; that rejection felt like a dagger. What I do, consume or dissipate by going out with my friends or other couples; it was a way to escape "(26 years old).

"My relationship was a kind of chewing gum; There was that dependence, that thing that I felt I was looking for and seeking, that I want more time from him; that rejection that I felt made me feel empty "(20 years).

A fourth theme found is the maintenance of emotional dependence when you have a consumer partner, expressed in the following units of analysis:

"The person with whom I replaced my ex-boyfriend was a person who distributed drugs, then I had contact with drugs, it was within my reach and at all times" (22 years).

"That relationship was drugs, alcohol and sex. For me it was very nice to have him while you were consuming "(49 years old).

"When I started to consume, it was because of my family, and I feel that I have an emotional dependence on him" (19 years old). 
"I started drinking with my partner and became a problem with my partner" (54 years old).

\section{Discussion}

The results suggest that women participating in the study had access to drugs, either directly or through a provider. It seems that the peer group continues to be the relational context that implicitly presses for consumption to begin, ${ }^{26}$ which would indicate a social skills deficit on the part of the group to avoid this risk. Although it was found that external factors such as those mentioned are important for the maintenance of the problem, the emotional dependence that has the couple is a personal factor shared by the group to continue with the consumption. In this sense, the study found quantitative and qualitative arguments to affirm that emotional dependence represents a risk factor for the problematic use of psychoactive substances in women users of the program, while increasing the probability of developing or maintaining problematic use, ${ }^{20-27}$ taking into account, of course, other conditions or risk factors. It is also observed that this influence is more frequent in the maintenance of the problem than in the beginning of it. Therefore, emotional dependence represents a risk factor for the initiation and maintenance of SPA consumption. A first observed aspect was that women with emotional dependence experience (and have experienced) a tendency to actively seek the attention and control of the couple (desire for control and domination) in order to have access to it at all times. This encourages them to tend to use various cognitive and behavioral strategies to please them. In this way, the consumption of psychoactive substances is a means that allows them to capture their attention ${ }^{10}$ or consumption can be a mitigating factor to reduce dysphoric emotions that they try to avoid, ${ }^{28,29}$ producing an interpretation of momentary relief, product of those behaviors of risk that are, for the most part, detrimental to their well-being.

Also, one of the characteristics of emotional dependence is fear or fear of relationship breakdown. Thus, the woman with emotional dependence, faced with a real or imagined situation of the relationship ending, will activate irrational beliefs and thoughts around loneliness, which will generate fear and intolerance to this situation and other dysphoric emotions. To not feel these emotions and avoid the feeling of loneliness, they resort to compensatory behaviors, such as behaviors aimed at retaking the relationship (supplications, persecution, promises of change, etc.), immediate search for another relationship, frequenting parties with friendships, (which can end in a sporadic sexual relationship) and consume SPA. ${ }^{22-28}$ It is convenient to indicate that the aforementioned compensatory behaviors are not exclusive, since the use of more than one of them was observed simultaneously. Another analysis obtained indicates that participants with emotional dependence tend to be submissive and subordinate in their relationships. Therefore, they will postpone or put their interests in second place. In this way, he tends to focus on his partner, they want that relationship to be exclusive and they gradually isolate themselves from their social environment. Therefore, they will give priority to the couple over anything else. They will wish that this attitude is reciprocal, that is to say that there is an affective correspondence, and although in many cases it is not so, they tolerate this emotional correspondence on the part of their partners. However, the fact that they persist in this attitude does not mean that they stop experiencing dysphoric emotions because of this non-reciprocity. Therefore, adopted as a strategy to continue to tolerate this situation and at the same time avoid the negative emotions indicated, resort to the consumption of SPA. ${ }^{21-29}$ On the other hand, the women in the sample who are emotionally dependent and have a consuming partner that provides them with SPA, intensify and perpetuate that dysfunctional personality trait. In this way, you will experience a greater affective need towards the other and there will be one more reason not to want to separate from it: the dependence on the substance, substance that is offered by your partner. ${ }^{19-21}$ It is important to point out that all these strategies are executed, often in a complementary way and that they are manifestations of the dimensions or factors that configure the emotional dependence, so they are based on the personality characteristics of the users. Although the present study has as its main limitation the size of the sample, the results allow knowing better the problem addressed and provides some guidelines for future studies on the role of emotional dependence as a risk factor in the consumption of SPA in women., constituting this the possibility of transfer of the study. Likewise, it allows designing thematic lines of treatment of emotional dependence in relation to drug addictions.

\section{Summary}

The aim of the study is to identify the influence of emotional dependence on the couple as a risk factor in the initiation and maintenance of the consumption of psychoactive substances in a sample of 20 women, users of a residential treatment program. For this, a mixed methodology and a concurrent transformative design were used. The results suggest that emotional dependence represents a risk factor for the consumption of psychoactive substances, this influence being more significant in the maintenance of the problem than in the beginning of it. Also, the processes by which this influence occurs imply cognitive and behavioral strategies aimed at avoiding dysphoric emotions, pleasing the couple, attracting attention and maintain the relationship. Based on the findings, it is suggested to include a program to address emotional dependence in order to optimize its effectiveness, both in the treatment activities and in the prevention of drug addiction in women.

\section{Acknowledgements}

None.

\section{Conflict of interest}

The author declares there is no conflict of interest.

\section{References}

1. World Health Organization. Neurociencia del consumo y dependencia de sustancias psicoactivas. Washington, DC; 2005.

2. World Health Organization. Clasificación internacional de las enfermedade-CIE 10. $10^{\text {th }}$ edition. Madrid: Meditor; 1992.

3. United Nations Office on Drugs and Crime. Informe Mundial sobre las Drogas 2017. Viena: United Nations; 2017.

4. Zavaleta A, Tapia L, Rojas M, et al. Epidemiología de Drogas en la Población Urbana Peruana 2013: Encuesta de Hogares. CEDRO. 2013.

5. Organization of American States. El problema de las drogas en las Américas: Estudios. Drogas y salud pública. Washington; 2013.

6. Centro de Información y Educación para la Prevención del Abuso de Drogas. El problema de las drogas en el Perú 2014. Lima; 2014.

7. Comisión Nacional para el Desarrollo y Vida sin Drogas. I Estudio sobre prevención y consumo de drogas en la población general de Lima Metropolitana y el Callao-2013. DEVIDA-Observatorio Peruano de Drogas; 2014. 
8. Becker J, Hu M. Sex Differences in Drug Abuse. Front Neuroendocrinol. 2008;29(1):36-47.

9. Gómez J, Arnal A, Martínez A, Muñoz D. Mujeres y uso del alcohol en las sociedades contemporáneas. Revista Española de Drogodependencias. 2010;35(3):273-284.

10. Llort A, Ferrando F. Borrás T, et al. El doble estigma de la mujer consumidora de drogas: estudio cualitativo sobre un grupo de auto apoyo de mujeres con problemas de abuso de sustancias. Alternativas. 2013;20:9-22.

11. Moral M, Sirvent C. Dependencia afectiva y género: perfil sintomático diferencial en una muestra de dependientes afectivos españoles. Interamerican Journal of Psychology. 2009;43(2):230-240.

12. Castelló J. Dependencia emocional: características y tratamiento. España: Alianza Editorial; 2005.

13. Castelló J. La superación de la dependencia emocional. Málaga: Ediciones Corona Borealis; 2012. p. 1-13.

14. Aiquipa JJ. Diseño y validación del Inventario de Dependencia Emocional-IDE. Revista de Investigación en Psicología. 2012;15(1): $133-145$.

15. Aiquipa JJ. IDE Inventario de dependencia emocional. México: El Manual Moderno; 2015.

16. Lemos M, Jaller C, González A, et al. Perfil cognitivo de la dependencia emocional en estudiantes universitarios en Medellín, Colombia Universitas Psycologica. 2012;11(2):395-404.

17. Riso W. Amar o depender? Barcelona: Editorial Planeta; 2014. p. 1-72.

18. Instituto de la Mujer. Mujer y drogas. Ministerio de Trabajo y Asuntos Sociales. Ministerio del Interior. Delegación del Gobierno para el Plan Nacional sobre Drogas. Madrid; 2003.

19. Arostegi E, Urbano A. La mujer drogodependiente: especificidad de género y factores asociados. Comunidad Autónoma Vasca: Instituto Deusto de Drogodependencias; 2004.

20. Instituto de Adicciones Madrid Salud. Mujer y adicción. Aspectos diferenciales y aproximación a un modelo de intervención. Madrid; 2005.

21. Castaños M, Meneses C, Palop M, et al. Intervención en drogodependencias con enfoque de género. Madrid: Instituto de la Mujer, Ministerio de Trabajo y Asuntos Sociales; 2007.

22. Pérez del Río F, Lara F, González-Gutierrez M. Abuso sexual, prostitución y dependencia afectiva en drogodependientes. Revista Española de Drogodependencias. 2010;35(3):365-378.

23. Teddlie CH, Tashakkori A. A General Typology of Research Designs Featuring Mixed Methods. Research in the Schools. 2006;13(1): 12-28.

24. Creswell J. Research Design: Qualitative, Quantitative, and Mixed Methods Approaches. $4^{\text {th }}$ edition. USA: SAGE Publications, INc; 2014.

25. Palinkas L, Horwitz S, Chamberlain P, et al. Mixed-Methods Designs in Mental Health Services Research: A Review. Psychiatric Services. 2011;62(3):255-263.

26. Barbosa A, Segura CA, Garzón D, et al. Significado de la experiencia del consumo de sustancias psicoactivas en un grupo de adolescentes institucionalizados. Avances en Psicología Latinoamericana. 2014;32(1):53-69.

27. Sánchez L, De Vicente P, Bolaños E. Necesidades terapéuticas de las mujeres drogodependientes atendidas en los Centros de Tratamiento Ambulatorios y Residenciales de Castilla y León. España: Junta de Castilla y León; 2010.

28. Stocco P, Llopis J, DeFazio L. Women drug abuse in Europe: Gender identity. España: Irefrea; 2000.

29. Pérez A, Correa M. Identidad femenina y consumo de drogas: un estudio cualitativo. Liberabit. 2011;17(2):211-222. 